\title{
Somaliland Bölgesi (Somali) Yağışlarının Trend Analizi
}

\author{
Trend Analysis of Somaliland Region Precipitation, Somalia
}

\author{
Kemal SAPLIOĞLU*,a, Abdishakur Osman DAHİR ${ }^{\text {b }}$ Tülay Suğra KÜÇÜKERDEM
}

Süleyman Demirel Üniversitesi, Mühendislik Fakültesi, İnşaat Mühendisliği Bölümü, 32260, Isparta

• Geliş tarihi / Received: 26.04.2017 • Düzeltilerek geliş tarihi / Received in revised form: 18.10.2017 • Kabul tarihi / Accepted: 24.10 .2017

\section{Öz}

Gerek artan nüfus gerekse sanayide hızlı ilerleme suya olan ihtiyacı son derece önemli hale getirmiștir. Bu yüzden eldeki su kaynaklarının optimum kullanılması ve yeni su kaynaklarının ortaya çıkarılması gerekliliği, planlama çalışmalarının en önemli konularından biri haline gelmiştir. Ancak çeşitli şartlardan dolayı oluşan ve varlığı pek çok bilim adamı tarafından dile getirilen küresel iklim değişikliği bu planlamanın yapılmasını zorlaştıran etmenlerdendir. Bu yüzden iklim değişikliği ve iklim değişikliklerinin mevcut su kaynaklarını etkileyip etkilemediği sorusu irdelenmeli ve kaynakların gelecekteki durumlarını nasıl etkileyeceği araştırılmalıdır. Bu çalışmada iklim değişikliğinden en çok etkilenen bölgelerden birisi olan ve Afrika'da bulunan Somali'nin Kuzeyindeki Somaliland bölgesindeki aylık ve yıllık yağış verilerinin trendleri irdelenmiştir. Bu irdelemede Mann-Kendall trend analizi, Şen grafik testi, Şen grafik testini baz alan ve Saplığlu tarafından teklif edilen istatistiksel method kullanılmıştır. Çalışmada bölgenin trendinin araştırılmasının yanı sıra trend testlerinin benzerlikleri ve farklılıkları da irdelenmiştir.

Anahtar kelimeler: İklim değişikliği, Mann-Kendall, Saplığlu grafik testi, Somaliland, Şen grafik testi, Trend analizi

\begin{abstract}
Both the population increase and the rapid advance in the industry have made the need for water very important. Hence the optimum usage of available water resources and the necessity for uncovering new water resources have become the most important issues of planning exercises. But, the global climate change which is occured because of various conditions and expressed by many scientists is one of the factors that makes this planning difficult. So the climate change and the question of whether climate change affect the available water springs or not must be inquired and also how it affects the water availability of the springs in the future must be investigated. In this study, monthly and annual rain fall data was examinated in the region of Somaliland where is placing on the Northern part of Somalia in Africa's one of the most affected regions. In this study, Mann-Kendall trend analysis, Sen's graphic test and the statistical method based on Sen's graphic test that is proposed by Saplioglu are used. In the study, the trend of the region was investigated and trend tests compared.
\end{abstract}

Keywords: Climate change, Mann-Kendall, Saplioglu graphic test, Somaliland, Sen's graphical test, Trend analysis

\footnotetext{
*a Kemal SAPLIOĞLU, kemalsaplioglu@ sdu.edu.tr; Tel: (0246) 21112 13; orcid.org/0000-0003-0016-8690

${ }^{\mathrm{b}}$ orcid.org/0000-0002-4965-8546 $\quad{ }^{\mathrm{c}}$ orcid.org/0000-0002-1102-1718
} 


\section{Giriş}

Son y1llarda iklim değişikliği ile ilgili bölgesel ve global ölçekli pek çok çalışma (Şen Z., 2014; Baria ve arkadaşları 2016) yapılmıştır. Bu çalışmaların büyük çoğunluğunda ise iklim değişikliğine yönelik önemli bulgular elde edilmiştir. Ancak elde edilen bu bilgilerin gerçeği yansıtıp yansıtmadığının iyi tespit edilmesi gerekmektedir. Bir bölgede iklim değişikliğinden söz edilebilmesi için on y1llar veya daha uzun süreli bir periyotta iklim ortalamalarında büyük farklılıklar olması gerekmektedir (Gocic \& Trajkovic, 2013). Global ölçekli bir iklim değişikliğinden söz edebilmek içinse bölgelerin birbirini etkilemesi gerekmektedir (Trajkovic \& Kolakovic, 2009).

Küresel bazda iklim değişimi çalışmalarının genellikle yağış (Nair ve arkadaşları 2014), sıcaklık ve akarsu debileri (Kumarve arkadaşları 2009) üzerine yoğunlaştı̆̆ görülmektedir. Bu çalışmaların bir kısmında ciddi oranda artış ve azalışlar mevcuttur. (Gregory, 1956) tarafından yapılan çalışmada İngiltere'deki yıllık yağış trendlerindeki değişimleri, (Suzuki, 1968) tarafindan yapılan çalışmada ise Japonya'daki yağış trendlerindeki değişimler çalışılmıştır. Yang ve Lu (2015) yaptıkları çalışmada çalışmamızda kullandığımız gibi Çinin kurak bir bölgesinde Mann-Kendall test istatistiğini uygulamışlardır. Jagannathan ve Parthasarathy (1973)(Jagannathan \& Parthasarathy, 1973) ve Parthasarathy ve Dhar, (1974)(Parthasarathy \& Dhar, 1974) tarafindan Hindistan'daki yağış verilerinden trend değişimi analiz edilmiştir. Ayrıca Goswami ve arkadaşları (2006) yaptıkları çalışmada Hindistan'daki yağışların \%80'ini oluşturan muson yağmurlarının trend değişimini irdelemişlerdir. Singh ve arkadaşları (2008) Hindistan'ın orta ve kuzey batı kesimlerindeki yağış verilerinin mevsimsel ve y1llık bazda trend değişimlerini incelemişlerdir. (Nasrallah \& Balling, 1995), 1950 ve 1990 y1llar1 arasındaki 41 yıllık sicaklık verilerini kullanarak Kuveyt için trend analizi yapmış ve $0.07^{\circ} \mathrm{C}$ sıcaklık artışı bulmuştur. Chen ve arkadaşları (2007) Çin'deki Hanjiang havzasında yaptıkları çalışmada \%95 güven derecesine göre herhangi bir sicaklık trendi tespit edememişler ancak yapılan çalışmalarda havzanın bazı kesimlerinde sıcaklık artışı gözlemlemişlerdir. Danjiangkou rezervuarında bu artışın $1^{\circ} \mathrm{C}-2^{\circ} \mathrm{C}$ arasında değiştiğini gözlemlemişlerdir. ElNesr (2010), Suudi Arabistan krallı̆̆ındaki 29 istasyona ait y1llı maksimum, minimum ve ortalama sicaklik değerlerini kullanarak trend analizi yapmışlardır.
Bu çalışmada kış aylarında (Kasım-Ocak) negatif trend olduğunu belirlemiştir.

Trend analizi çalışmalarında en çok kullanılan yöntem Mann-Kendall yöntemi olup Şen testi, Şen'in grafiksel metodu, Spearman's testi ve Regresyon analizleri karşımıza çıkmaktadır. Mann-Kendall testi hidrometeorolojik verilerin analizinde siklıkla kullanılmaktadır (Yue ve arkadaşları 2002). Mann-Kendall testinde elde edilen değerlerin belirli limit değerlerinin dışına çıkması durumunda pozitif veya negatif yönde trend varlığından söz edilebilir (Bayazıt \& Önöz, 2007). Wang ve arkadaşları (2004) Batı Çin'de yağış verileri üzerine Mann-Kendall testi uygulamışlar ve yağışlarda önemli ölçüde büyük artışlar olduğunu tespit etmişlerdir. (Partal \& Kahya, 2006), Türkiye'de yaptıkları çalışmada 96 yă̆ış ölçüm istasyonu üzerinde incelemeler yapmışlar ve 14 noktada Ocak ayında önemli derecede azalış trendi bulmuşlardır. Satyamury ve arkadaşları (2010), Amazon havzası üzerinde bulunan 18 farklı istasyondan aldıkları yağış verilerinin trendini Mann-Kendall trend testi ile incelemişlerdir. $\mathrm{Bu}$ çalışmada 6 istasyonun verilerinde ciddi şekilde bir artış trendi olduğunu tespit etmişlerdir. (Tabari, Somoe, \& Zadeh, 2011) iklim değişimi üzerine yaptıkları çalışmada İran'ın güneybatı k1smına ait 13 istasyonu çalışmışlardır. 1966-2005 yılları arasındaki verilerle çalıştıkları bu çalışmada 1970'erden başlayan ortalama $0.412^{\circ} \mathrm{C}$ lik bir artış trendi elde etmişlerdir. $\mathrm{Bu}$ çalışmada kullanılan MannKendall, Mann-Whitney ve Mann-Kendall sıralama testlerinin üçü de bulunan sonuçları destekler niteliktedir. (Karmesha, 2012) Amerika Birleşik Devletleri'nin kuzeydoğusunda bulunan 9 eyalette 1900-2011 yılları arasındaki veriler ile yaptığı çalışmada, yağış ve sicaklık trendlerini tespit etmeye çalışmıştır. Bu çalışmalarda hem sicaklık değerlerinde hem de yağış değerlerinde istatistiksel öneme sahip artı̧̧ trendleri tespit etmiştir. (Gocic \& Trajkovic, 2013) Sırbistan'da yağış verileri üzerine yaptıkları çalışmada MannKendall ve Spearman's testlerinde \%95 önem derecesine sahip artış ve azalış trendleri tespit etmişlerdir. (Mohamed \& Saavaenije, 2014) Nil nehri çevresinde bulunan Sudd havzasında hem yerel hem de bölgesel bazda genel trend değişimlerini tespit edebilmek için Mann-Kendall test istatistiğini kullanmışlardır. $\mathrm{Bu}$ çalışmada 1900-2000 yılları arasinda bulunan 100 y1llık veriler kullanılmıştır. $\mathrm{Bu}$ havzada yaptıkları çalışmada bulunan en çarpıcı sonuçlar 1960 yılı ve sonrasinda Victoria gölünde meydana gelen trend artışının yanı sıra maksimum ve minimum sicaklık değerlerinde meydana gelen 0,6 ve $1,5^{\circ} \mathrm{C}$ 
lik artış miktarlarıdır. (Ageena, Macdonald, \& Morse, 2014) Libya'da 1945-2009 yılları arasında yaptıkları ve Mann-Kendall test istatistiğini kullandıkları çalışmada sıcaklık değerlerinde önemli ölçüde negatif trend olduğunu tespit etmişlerdir.

Bu çalışmada ise Afrika'da yer alan Somali'nin üç ana bölgesinden biri olan ve Somali'nin kuzeyinde bulunan istasyonlardan gerekli veri sayısına sahip 5 istasyondan alınan aylık ve yıllık veriler, hem Mann-Kendall hem de Şen grafik testine göre analiz edilmiştir. Ayrıca bu istasyonların ait olduğu bölgelerdeki yağış değerlerinin 100 y1llık dönemde uğrayabileceği değişim miktarları da hesaplanmıştır. Son olarak Saplığlu (2015) tarafindan önerilmiş olan ve Şen grafik testinin istatistiksel çözümü olan istatistiksel yöntemle de trendler test edilmiştir.

\section{Materyal ve Metot}

\section{1. Çalışmada Kullanılan Materyal}

Somali lkesi çalışma bölgesi eyalet olarak 3 bölgeye ayrılmaktadır. Somali'nin kuzeyinde Somaliland bölgesi, kuzey doğusunda Puntland ve güneyinde Güney ve Orta Somali olarak adlandırılan kısım bulunmaktadır. Çalışmada kullanılan veriler kuzeyinde bulunan Somaliland bölgesine aittir (Şekil 1) (Wikivoyage, 2015).. Çalışmada Somaliland'ın Adwal bölgesine ait

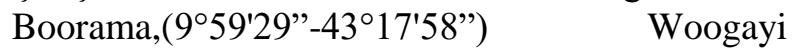
bölgesine ait Berbera $\left(10^{\circ} 26^{\prime} 20^{\prime \prime}-{ }^{\circ} 44^{\circ} 0^{\prime} 37^{\prime \prime}\right)$ ve Hergerisa ( $\left.9^{\circ} 33^{\prime} 46^{\prime \prime}-44^{\circ} 4^{\prime} 9^{\prime \prime}\right)$, Togdheer bölgesine

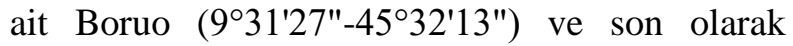
Sanaag bölgesine ait Erigabo $\left(10^{\circ} 37^{\prime} 5^{\prime \prime}-47^{\circ} 22^{\prime} 12\right)$ yağış ölçüm istasyonundan alınan veriler kullanılmıştır.

Somaliand bölgesinin yıllık ortalama yağış miktarı $267 \mathrm{~mm}$ dir. Bölgenin en çok yağış alan kısmı yıllık ortalama $300 \mathrm{~mm}$ yağış yüksekliğine sahip olan Togdheer bölümüdür. En az yağış alan kesimi ise $198 \mathrm{~mm}$ ortalamasiyla Sool bölgesidir. $\mathrm{Bu}$ bölgedeki istasyonlara ait veriler elde edilmiş ve bu verilerin öncelikle sayısının trend analiz yapmak için uygun olup olmadığ 1 değerlendirilmiştir. Bütün istasyonların genel özelliği Somali'de çıkan iç savaşın başlangıç yılı olan 1990'dan sonra veri alınamamış olmasıdır. 1990 yılından sonra belli bir boşluk oluşan bu istasyonların bazıları 1997 yılında tekrar faaliyete geçmiş, bazılarının faaliyete geçme süresi ise 2007 yılını bulmuştur. Somali'nin kuzey kesiminde bulunan bölgeye ait toplam 35 adet istasyon tespit edilmiştir. Ancak bu istasyonlardan sadece 5 tanesi trend analizi yapılabilecek kadar veriye sahip olduğu anlaşılmıştır.

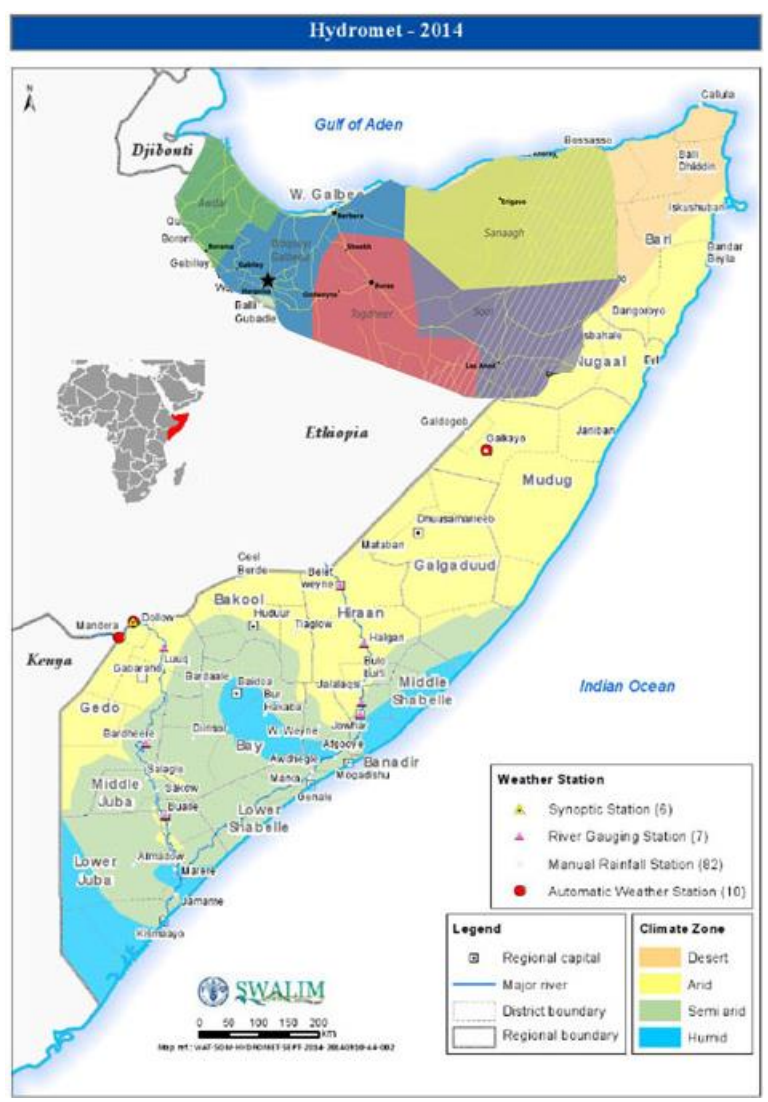

Şekil 1. Somaliland bölgesinin alt bölgeleri

\section{1. Çalışmada Kullanılan Yöntemler}

\subsubsection{Mann-Kendall Testi}

Parametrik olmayan bir test olan Mann-Kendall test istatistiği sıfir hipotezine dayanan ve zamansal serileri kullanan bir istatistiksel yöntemdir. $\mathrm{Bu}$ yöntemde ilk kurulan hipotez trendin olmadığına yönelik olan hipotezdir. Bu istatistiksel yöntemde zaman serileri iki gruba ayrılır (Saplığlu, 2015). Bu gruplardan birincisi zaman serisinin sondan başa doğru sıralanmış hali, ikincisi ise zaman periyodunun baştan sona doğru sıralanmış halidir. Öncelikle ilk serideki her i'inci terimin $\mathrm{i}+1-n$ 'inci terim aralı̆̆ındaki seri elemanları ile kıyaslaması yapılır. Şayet söz konusu terim, kıyaslandığ 1 terimden büyük ise +1 say1 eklenir. Kiyaslama bittikten sonra verilen bütün +1 ler toplanır ve bu toplam $P$ ile gösterilir. $\mathrm{Bu}$ aşamada yapılan işlemlerin aynısı ikinci seri için de tekrarlanır buradan elde edilen toplam ise M ile gösterilir. İşlemler bittikten sonra oluşturulan istatistik de $\mathrm{S}$ ile gösterilir. $\mathrm{S}$ ise Denklem 1'de gösterildiği gibi ifade edilir.

$S=P-M$ 
Veri sayısının 10'dan fazla olduğu serilerde test istatistiği aşağıdaki gibi ifade edilebilir (Denklem 2).

$\mu_{\mathrm{s}}=0$ ve $\sigma_{\mathrm{s}}=\sqrt{\mathrm{n}(\mathrm{n}-1)(2 \mathrm{n}+5) / 18}$

Denklem 3 ile elde edilen $Z$ değeri istatistiksel olarak hipotezin reddi veya kabulu için kullanılmaktadır. Şayet $\mathrm{Z} / 2$ değeri normal dağılımda $\alpha$ önem derecesi ile belirlenmiş olan değerden küçük bir değer alırsa bu durumda hipotez kabul edilir ve trendin olmadığı varsayılır. Daha büyük bir değer alması durumunda trend oluştuğu kabulü yapılır. (Yue \& Hashino, 2003).

$$
\mathrm{z}=\left[\begin{array}{cc}
\frac{\mathrm{s}-1}{\sigma_{\mathrm{s}}} & \mathrm{s}>0 \\
0 & \mathrm{~s}=0 \\
\frac{\mathrm{s}+1}{\sigma_{\mathrm{s}}} & \mathrm{s}<0
\end{array}\right]
$$

\subsection{2. Şen Grafik Testi}

(Şen Z. , 2012) tarafından kartezyen koordinat sistemini üzerinde 1:1 çizgisine bağlı bir trend analiz metodu ortaya konmuştur. Buradaki 1:1 çizgisi ve bu çizgiye yakın bölgeler trendin olmadığı kısmı ifade etmektedir. 1:1 çizgisinin her iki tarafinda da üçgensel alanlar mevcuttur. $\mathrm{Bu}$ üçgensel alanlar trendin oluşumu ve yönü ile ilgili bilgiler içerir (Şekil 2). Öncelikle zaman serili veriler sayıları eşit olan iki gruba ayrılır. Bu serilerden birincisi zaman serisini başlangıcından orta noktadaki veriye kadar olan zaman aralığındaki veriler, ikincisi ise orta noktadaki veri ile zaman serisinin son verisi arasındaki verilerdir. $\mathrm{Bu}$ verilerin her ikisi de kendi içerisinde büyükten küçüğe sıralanır. Birinci grup veriler $\mathrm{x}$ eksenine ikinci grup veriler de y eksenine gelecek şekilde saçılım diyagramları oluşturulur. Son olarak bu saçılım diyagramının tam ortasından 1:1 çizgisi geçirilir. Saçılım diyagramında elde edilen sonuçlar 1:1 çizgisinin altında kalırsa trendin azalma yönünde olduğu, üzerinde ise trendin artış yönünde olduğu kabul edilebilir. (Şen Z. , 2012; Şen Z. , 2014)

\subsection{3. Şen Testi İstatistiksel Analizi}

$\mathrm{Bu}$ yöntem Şen'in grafik testinden esinlenerek oluşturulmuş bir yöntemdir. Bu yöntemde de Şen testinde olduğu gibi veriler eşit olarak iki kısma ayrılır ve küçükten büyüğe doğru sıralanır. Daha sonraki aşmada ikinci data setinin birinci değerinden birinci data setinin birinci değeri çıkartılır.

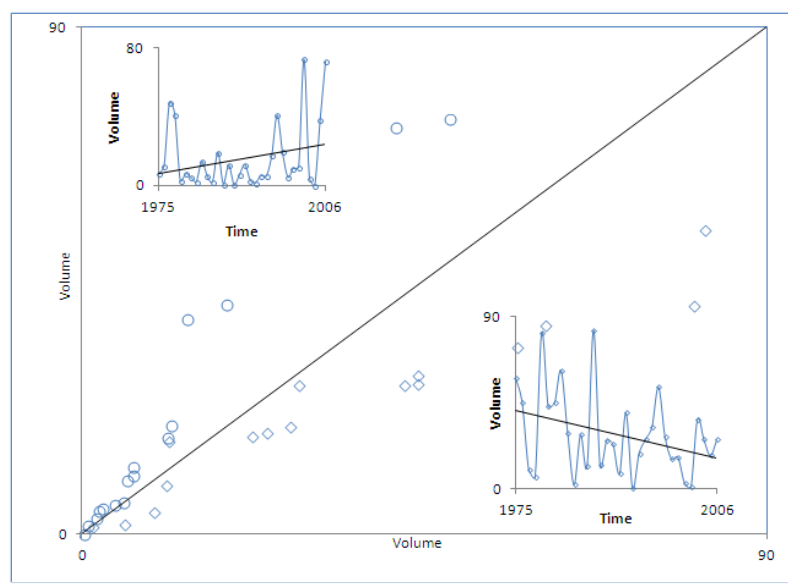

Şekil 2. Trend artış ve azalışlarının Şen grafik testi ile gösterimi

Sonra ikinci data setinin ikinci değerinden birinci data setinin ikinci değeri çıkartılır. Bu işlem tüm veriler bitinceye kadar devam ettirilir. Bir sonraki aşamada ise elde edilen bütün değerlerin ortalaması tespit edilir (Denklem 4).

$\mathrm{MX}=\sum_{\mathrm{i}=1}^{\mathrm{n}}\left(\mathrm{X}_{2 \mathrm{i}}-\mathrm{X}_{1 \mathrm{i}}\right) / \mathrm{n}$

Burada $\mathrm{i}$ indis, $\mathrm{X}_{1}$ birinci data seti, $\mathrm{X}_{2}$ ikinci data seti $n$ her bir data setindeki veri sayıs1 ve MX ise data setleri arasındaki verileri farklarının ortalamasidır. Birinci data seti verilerin ilk yarısını kapsadığından dolayı, sonuçların eksi çıkması durumunda negatif bir trend, artı çıkması durumunda da pozitif bir trend oluştuğu düşünülür (Saplığlu, 2015).

\section{Araştırma ve Bulgular}

Çalışmanın bu kısmında Somaliland'ın Adwal bölgesine ait Boorama, Woogayi bölgesine ait Berbera ve Hergerisa, Togdheer bölgesine ait Boruo ve son olarak Sanaag bölgesine ait Erigabo yağış ölçüm istasyonundan alınan veriler ile yapılan analizler; tablolar ve çizelgeler şeklinde özetlenmeye çalışılmıştır.

\subsection{Boorama Bölgesi}

$\mathrm{Bu}$ bölgedeki aylık ve yıllık verilerin MannKendall test istatistiği ile test edilmiş sonuçlarına bakıldığında sadece Haziran ayında \%95 güven aralığında bir trend olduğu görülebilmektedir. (Tablo 2). \%90 güven aralığına bakıldığında ise Ocak ve Haziran aylarında negatif bir trendin 
olduğu söylenebilir. Ayrıca 8 adet aylık verinin ve yıllık toplam yağış yüksekliği verisinin negatif eğilimli, 4 adet aylık verinin ise pozitif eğilimli olduğu görülmektedir.

Şekil 3'de Boorama bölgesine ait Şen grafik testi sonuçları verilmiştir. Bu sonuçlara göre 7 adet veride azalan trend, 2 adet veride de artan trend bulunmuştur. Ayrica Şen grafik testine tabi tutulan veriler, Saplıoğlu tarafından önerilen trend testi ile de incelenmiş ve sonuçlar Şen testi ile kıyaslamalı olarak gösterilmiştir (Tablo 1 ve Tablo 2).

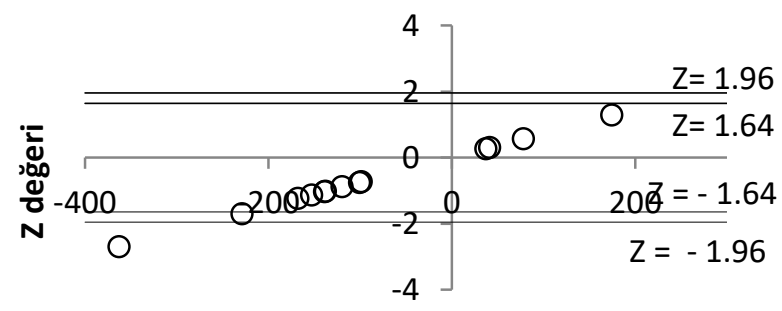

$S$ değeri

Şekil 3. Boorama bölgesi $\% 90$ ve $\% 95$ güven aralığına göre trendleri

\subsection{Berbera Bölgesi}

Berbera bölgesinin y1ll1k ve aylık verileri MannKendall test istatistiği ile test edilmiş ve bölgeye ait trendler bulunmuştur. Ayrıca regresyon analizleri yapılarak denklem takımları oluşturulmuş ve yıllık değişim miktarları tespit edilmeye çalışılmıştır.

Şekil 5 incelendiğinde \% 95 güven aralığında 4 adet veri setinde azalan bir trend olduğu gözlemlenmektedir. Yine bu grafiğe göre 5 adet veride de $\% 90$ güven aralığında azalan bir trend olduğu tespit edilebilir. \% 95 güven aralığına göre Ocak, Şubat ve Mayıs aylarının yanı sira yıl genelinde de azalan bir trend söz konusudur. Yine bu çizelgeye göre $\% 90$ güven aralığında yapılan incelemede bu aylara Aralık ayı da katılmaktadır.

Ayrıca bu grafik ve çizelgelere bakıldığında artan bir trendin veya eğilimin bulunmadığ gözükmektedir. \%95 güven aralığında azalış trendine sahip olan y1llık eğiliminde $0.22 \mathrm{~mm}$ lik bir azalış söz konusudur.

Şen testine göre 6 farklı ayda ve y1llık bazda trend olduğu ve bu trendlerin bu modeli baz alan test istatistiği ile ispatlandığ 1 görülmektedir (Tablo 4). Ayrıca Şen grafik testi için çizilen grafikler Şekil 6'da gösterilmiştir. Mann-Kendall testinde trendin var olduğu gözüken Ocak, Şubat, Mayıs ve yıllık yağış miktarlarının da bu testlerle desteklendiği görülmektedir. Mann-Kendall test istatistiğine göre trend oluşumu belirlenememiş olan Temmuz ve Ekim aylarında son yıllar itibari ile oldukça düşük yağışlar gözlemlenmiştir. Yağış oranı oldukça az olan bölgede verilerin ilk yarısı itibari ile Temmuz ayında $2.7 \mathrm{~mm}$ 'lik bir ortalama yă̆ış söz konusu iken ikinci yarısında $0.5 \mathrm{~mm}$ 'lik bir yağı̧ söz konusudur. Ekim ayında da bu durum verilerin ilk yarısında $1.7 \mathrm{~mm}$ iken ikinci yarı verilerde bu oran $0.3 \mathrm{~mm}$ ye kadar düştüğü görülmektedir.

Mann-Kendall testi; Şen grafik testi ve Saplıoğlu testleri birlikte incelendiğinde, Mann-Kendall testlerinde daha az sayida trend bulunduğu görülmektedir. Şen grafik testinde açikça görülen testlerin bile bazı durumlarda Mann-Kendall testinde bulunamamasının, verilerin homojen olmamasından dolayı olduğu söylenebilir.

Tablo 1. Boorama bölgesi Mann-Kendall test istatistiği sonuçları.

\begin{tabular}{|c|c|c|c|c|c|c|}
\hline Aylar & Ortalama Yağış (mm) & $\mathbf{S}$ & $\mathbf{Z}$ & $\begin{array}{c}\begin{array}{c}\text { 100Yıllık değişim } \\
(\mathrm{mm})\end{array} \\
\end{array}$ & Trend $\mathrm{Z}(\mathbf{0 , 9 5 )}$ & Trend $\mathrm{Z}(\mathbf{0 , 9 0 )}$ \\
\hline Ocak & 8.44 & -229 & $-1,69$ & -21 & $\leftrightarrow$ & $\downarrow$ \\
\hline Şubat & 16.10 & -101 & $-0,75$ & -12 & $\leftrightarrow$ & $\leftrightarrow$ \\
\hline Mart & 39.04 & 41 & 0,30 & 2 & $\leftrightarrow$ & $\leftrightarrow$ \\
\hline Nisan & 82.40 & 174 & 1,29 & 38 & $\leftrightarrow$ & $\leftrightarrow$ \\
\hline May1s & 54.38 & 37 & 0,27 & 4 & $\leftrightarrow$ & $\leftrightarrow$ \\
\hline Haziran & 30.57 & -363 & $-2,7$ & -31 & $\downarrow$ & $\downarrow$ \\
\hline Temmuz & 68.43 & -139 & $-1,03$ & -4 & $\leftrightarrow$ & $\leftrightarrow$ \\
\hline A ğustos & 110.30 & -168 & $-1,24$ & -14 & $\leftrightarrow$ & $\leftrightarrow$ \\
\hline Eylül & 76.29 & 78 & 0,57 & 7 & $\leftrightarrow$ & $\leftrightarrow$ \\
\hline Ekim & 13.78 & -99 & $-0,73$ & 2 & $\leftrightarrow$ & $\leftrightarrow$ \\
\hline Kasım & 12.21 & -153 & $-1,13$ & -14 & $\leftrightarrow$ & $\leftrightarrow$ \\
\hline Aralık & 2.76 & -120 & $-0,88$ & -1 & $\leftrightarrow$ & $\leftrightarrow$ \\
\hline Y1llik & 514,7 & -138 & $-1,02$ & -51 & $\leftrightarrow$ & $\leftrightarrow$ \\
\hline
\end{tabular}



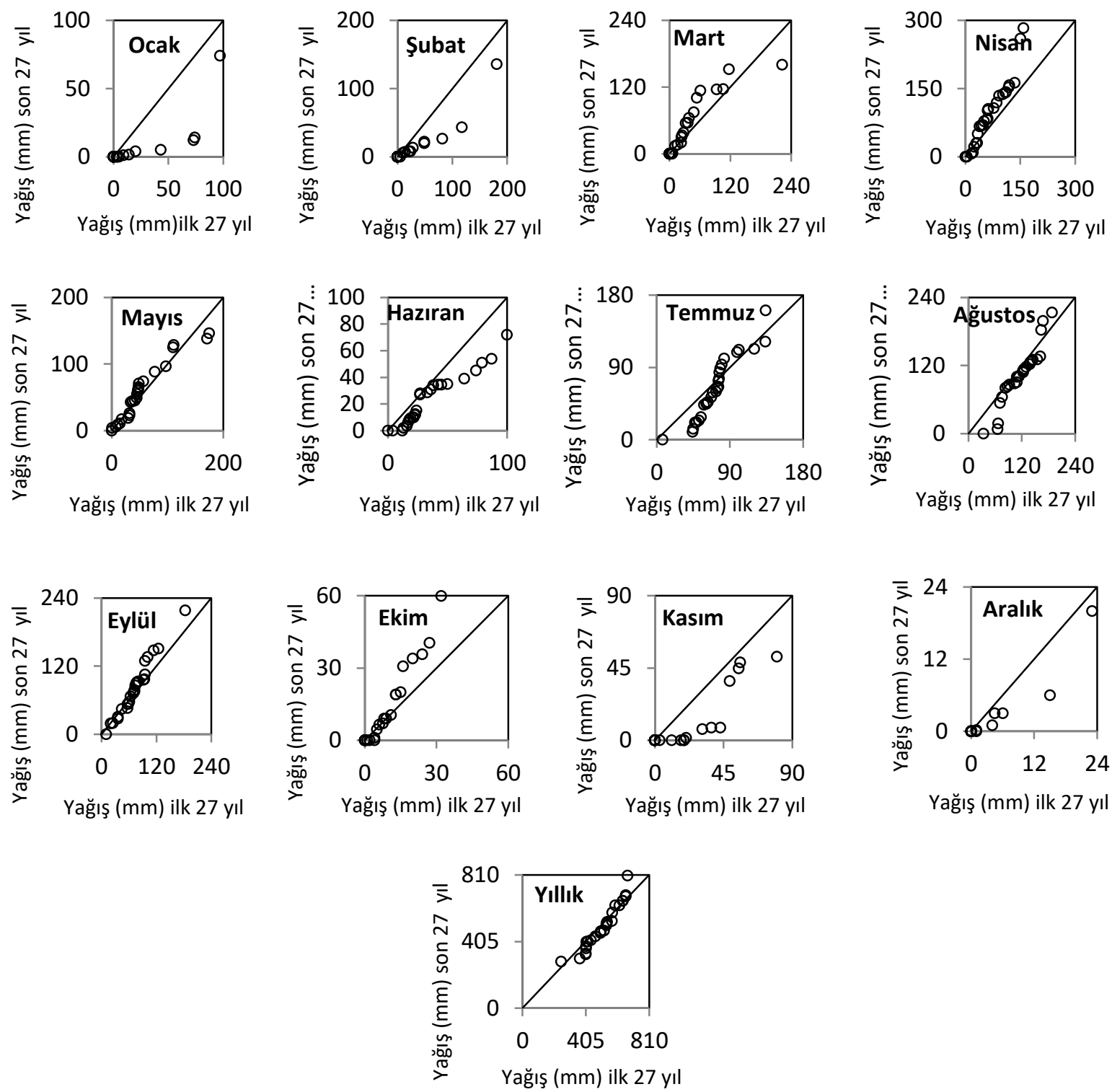

Şekil 4. Boorama İstasyonu aylık ve yıllık bazda Şen testi sonuçları

Tablo 2. Boorama istasyonu istatistiksel test sonuçları ile Şen testinin karşılaştırılması

\begin{tabular}{lccccccc}
\hline Aylar & $\begin{array}{c}\text { Veri } \\
\text { Sayısı }\end{array}$ & $\begin{array}{c}\text { Toplam } \\
\text { Fark }\end{array}$ & $\begin{array}{c}\text { Standart } \\
\text { Hata }\end{array}$ & $\begin{array}{c}\text { Hata } \\
\text { Ortalaması }\end{array}$ & $\begin{array}{c}\text { Test } \\
\text { Istatistiği }\end{array}$ & $\begin{array}{c}\text { \%95 (G.A.) test } \\
\text { (t test 2,05) }\end{array}$ & $\begin{array}{c}\text { Şen Grafik } \\
\text { Testi }\end{array}$ \\
\hline Ocak & 27 & $-232,5$ & 17,02 & $-8,61$ & $-2,63$ & $\downarrow$ & $\downarrow$ \\
\hline Subat & 27 & $-291,4$ & 19,06 & $-10,79$ & $-2,94$ & $\downarrow$ & $\leftrightarrow$ \\
\hline Mart & 27 & 207,7 & 20,72 & 7,69 & 1,93 & $\leftrightarrow$ & $\uparrow$ \\
\hline Nisan & 27 & 747,6 & 30,01 & 27,69 & 4,80 & $\uparrow$ & $\leftrightarrow$ \\
\hline Mayıs & 27 & 86,70 & 12,91 & 3,21 & 1,29 & $\leftrightarrow$ & $\downarrow$ \\
\hline Haziran & 27 & -322.30 & 8.95 & -11.94 & $-6,93$ & $\downarrow$ & $\downarrow$ \\
\hline Temmuz & 27 & -223.40 & 15.71 & -8.27 & -2.74 & $\downarrow$ & $\leftrightarrow$ \\
\hline Ağustos & 27 & -348.40 & 17.94 & $-12,90$ & -3.74 & $\downarrow$ & $\uparrow$ \\
\hline Eylül & 27 & 121.30 & 16.34 & 4,49 & 1.43 & $\leftrightarrow$ & $\downarrow$ \\
\hline Ekim & 27 & 140.20 & 9.09 & 5.19 & 2.97 & $\uparrow$ & $\downarrow$ \\
\hline Kasım & 27 & -233.90 & 10.91 & -8.66 & -4.13 & $\downarrow$ & $\leftrightarrow$ \\
\hline Aralık & 27 & 35.20 & 10.40 & 1.30 & 0.65 & $\leftrightarrow$ & $\leftrightarrow$ \\
\hline Y1llık & 27 & -313.20 & 48.31 & -11.60 & -1.25 & $\leftrightarrow$ & $\downarrow$ \\
\hline
\end{tabular}




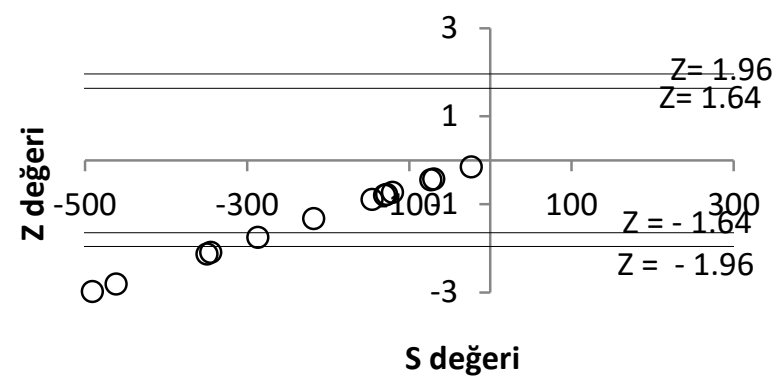

Ayrıca Mann-Kendall testinde çok büyük olan farklar ile çok küçük olan farklar aynı ağırlığa sahiptir. Ancak Şen testi ve Saplıoğlu testlerinde bu farkların daha çok önem kazandığını görmekteyiz.

Şekil 5. Berbera bölgesi $\% 90$ ve $\% 95$ güven aralığına göre trendleri.

Tablo 3. Berbera bölgesi Mann-Kendall test istatistiği sonuçları

\begin{tabular}{lcccccc}
\hline Aylar & $\begin{array}{c}\text { Ortalama Yağıș } \\
(\mathbf{m m})\end{array}$ & $\mathbf{S}$ & $\mathbf{Z}$ & $\begin{array}{c}\text { 100Yıllık } \\
\text { değișim } \mathbf{( m m})\end{array}$ & $\begin{array}{c}\text { Trend Z } \\
(\mathbf{0 , 9 5})\end{array}$ & $\begin{array}{c}\text { Trend Z } \\
(\mathbf{0 , 9 0})\end{array}$ \\
\hline Ocak & 3.91 & -350 & $-2,12$ & -4.5 & $\downarrow$ & $\downarrow$ \\
\hline Şubat & 3.58 & -491 & $-2,97$ & -5.6 & $\downarrow$ & $\downarrow$ \\
\hline Mart & 6.92 & -128 & $-0,77$ & -13 & $\leftrightarrow$ & $\leftrightarrow$ \\
\hline Nisan & 9.25 & -146 & $-0,88$ & -5.2 & $\leftrightarrow$ & $\leftrightarrow$ \\
\hline Mayıs & 6.10 & -345 & $-2,08$ & -10.5 & $\downarrow$ & $\leftrightarrow$ \\
\hline Haziran & 0.45 & -70 & $-0,42$ & -0.3 & $\leftrightarrow$ & $\leftrightarrow$ \\
\hline Temmuz & 1.40 & -218 & $-1,32$ & -1.9 & $\leftrightarrow$ & $\leftrightarrow$ \\
\hline Ağustos & 3.01 & -121 & $-0,72$ & 5.6 & $\leftrightarrow$ & $\leftrightarrow$ \\
\hline Eylül & 1.72 & -131 & $-0,79$ & -0.8 & $\leftrightarrow$ & $\leftrightarrow$ \\
\hline Ekim & 1.51 & -74 & $-0,44$ & -3.3 & $\leftrightarrow$ & $\downarrow$ \\
\hline Kasim & 5.55 & -24 & $-0,14$ & 16 & $\leftrightarrow$ & $\downarrow$ \\
\hline Aralık & 2.98 & -287 & $-1,74$ & 1.1 & $\leftrightarrow$ & $\downarrow$ \\
\hline Y1ll1k & 46.36 & -462 & $-2,80$ & -22 & $\downarrow$ & $\leftrightarrow$ \\
\hline
\end{tabular}

Tablo 4. Berbera istasyonu istatistiksel test sonuçları ile Şen testinin karşılaştırılması

\begin{tabular}{lccccccc}
\hline Aylar & $\begin{array}{c}\text { Veri } \\
\text { Sayısı }\end{array}$ & $\begin{array}{c}\text { Toplam } \\
\text { Fark }\end{array}$ & $\begin{array}{c}\text { Standart } \\
\text { Hata }\end{array}$ & $\begin{array}{c}\text { Hata } \\
\text { Ortalaması }\end{array}$ & $\begin{array}{c}\text { Test } \\
\text { İstatistiği }\end{array}$ & $\begin{array}{c}\text { \%95 (G.A.) } \\
\text { test } \\
\text { (z test 1,96) }\end{array}$ & $\begin{array}{c}\text { Şen Grafik } \\
\text { Testi }\end{array}$ \\
\hline Ocak & 31 & $-79,35$ & 6,61 & $-2,56$ & $-2,15$ & $\downarrow$ & $\downarrow$ \\
\hline Şubat & 31 & $-127,04$ & 8,20 & $-4,10$ & $-2,78$ & $\downarrow$ & $\downarrow$ \\
\hline Mart & 31 & $-109,58$ & 15,18 & $-3,53$ & $-1,30$ & $\leftrightarrow$ & $\leftrightarrow$ \\
\hline Nisan & 31 & $-192,38$ & 9,59 & $-6,21$ & $-3,60$ & $\downarrow$ & $\downarrow$ \\
\hline Mayis & 31 & $-179,31$ & 10,67 & $-5,78$ & $-3,02$ & $\downarrow$ & $\downarrow$ \\
\hline Haziran & 31 & 16,09 & 3,42 & 0,52 & 0,84 & $\leftrightarrow$ & $\leftrightarrow$ \\
\hline Temmuz & 31 & $-58,28$ & 3,84 & $-1,88$ & $-2,73$ & $\downarrow$ & $\leftrightarrow$ \\
\hline Ağustos & 31 & 46,55 & 9,15 & 1,50 & 0,91 & $\leftrightarrow$ & $\leftrightarrow$ \\
\hline Eylül & 31 & 9,90 & 1,90 & 0,32 & 0,94 & $\leftrightarrow$ & $\leftrightarrow$ \\
\hline Ekim & 31 & $-74,10$ & 6,41 & $-2,39$ & $-2,08$ & $\downarrow$ & $\leftrightarrow$ \\
\hline Kasim & 31 & 80,83 & 27,18 & 2,61 & 0,53 & $\leftrightarrow$ & $\leftrightarrow$ \\
\hline Aralı & 31 & 28,86 & 9,35 & $-0,93$ & 0,55 & $\leftrightarrow$ & $\downarrow$ \\
\hline Y1llik & 31 & $-637,31$ & 21,31 & $-20,57$ & $-5,38$ & $\downarrow$ & $\downarrow$ \\
\hline
\end{tabular}



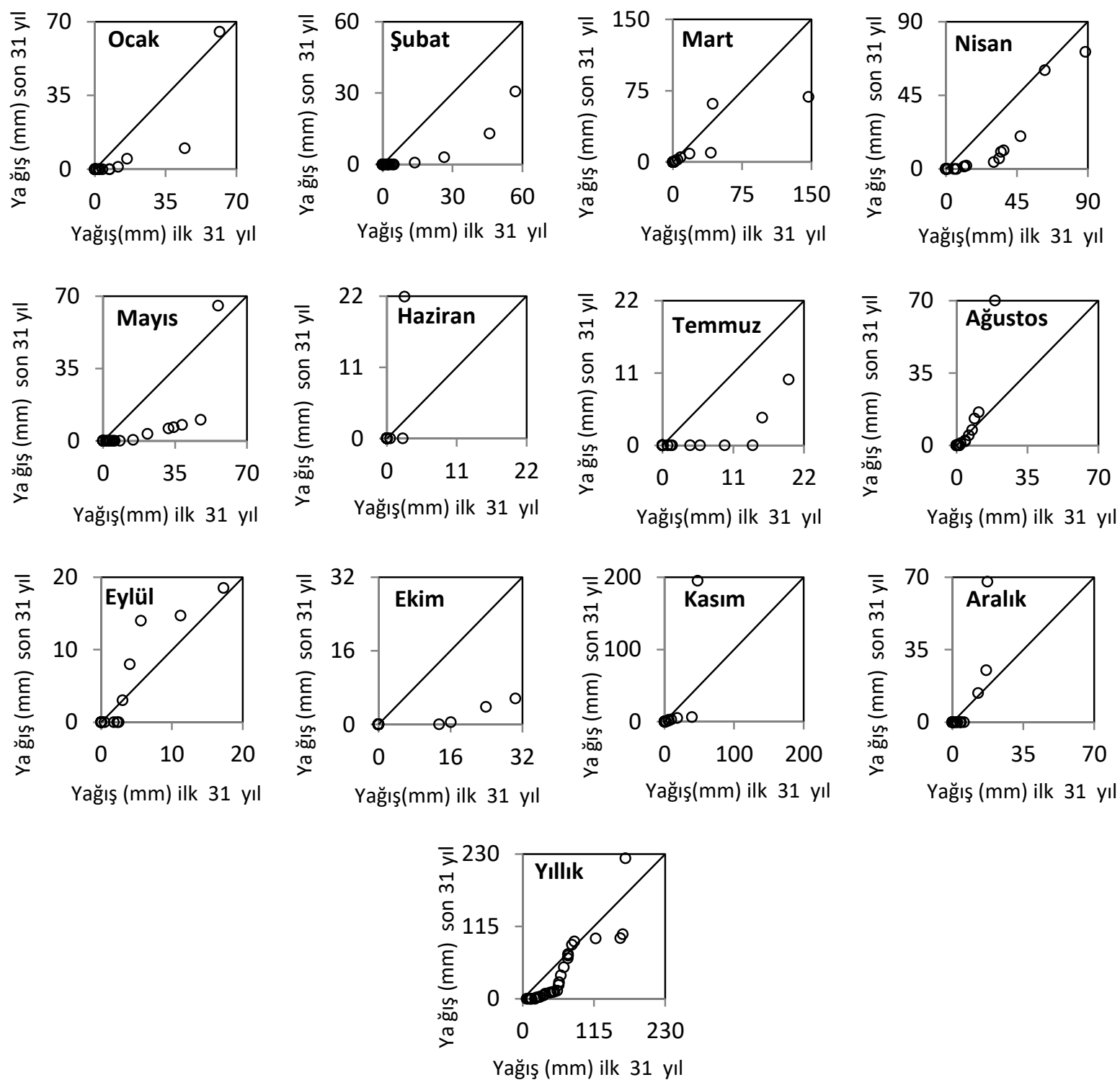

Şekil 6. Berberea İstasyonu aylık ve yı1lık bazda Şen testi sonuçları

\subsection{Hergeisa Bölgesi}

Hergeisa bölgesi için Mann-Kendall test istatistiği sonuçlarına göre Haziran ve Ağustos aylarında önemli oranlarda azalışların olduğu tespit edilmiştir (Tablo 5). İstatistiksel sonuçların sadece 2 tanesi \%95 güven aralığında olmasına karşın 3 tanesinin de $\% 90$ güven aralığına çok yakın olduğu görülmektedir (Şekil 7).

72 yıllık veri setinin ikiye bölünmesiyle elde edilen Şen grafik testi sonuçları ve bu testlerin istatistiksel analizi olan ve Saplığlu tarafindan önerilen istatistiksel analizin sonuçları Tablo 6'da özetlenmeye çalışılmıştır. $\mathrm{Bu}$ sonuçlara göre grafiksel metotta 4 adet trend gözlemlenmişken istatistiksel analizde 6 adet trend gözükmektedir.

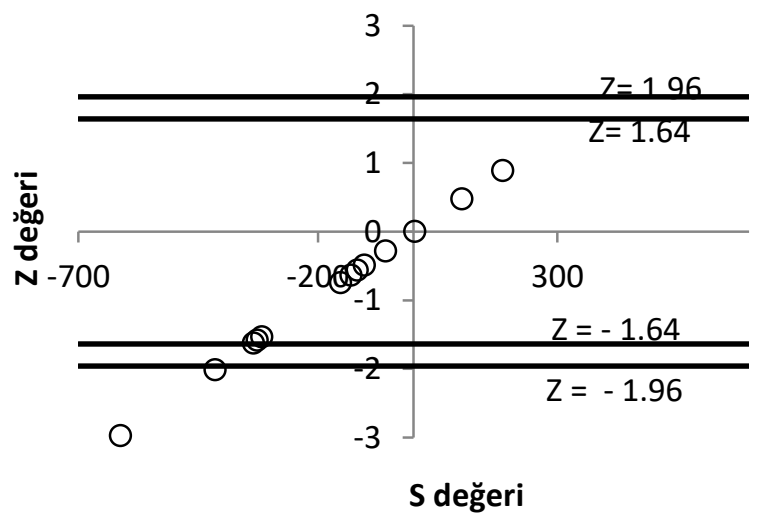

Şekil 7. Hergeisa Bölgesi $\% 90$ ve $\% 95$ güven aralığına göre trendleri 
Tablo 5. Hergeisa Bölgesi Mann-Kendall test istatistiği sonuçları

\begin{tabular}{lcccccc}
\hline Aylar & $\begin{array}{c}\text { Ortalama Yağıs } \\
(\mathbf{m m})\end{array}$ & $\mathbf{S}$ & $\mathbf{Z}$ & $\begin{array}{c}\mathbf{1 0 0 Y} \text { Illık } \\
\text { değişim }(\mathbf{m m})\end{array}$ & Trend Z (0,95) & Trend Z (0,90) \\
\hline Ocak & 2.69 & -335 & -1.62 & -5.2 & $\leftrightarrow$ & $\leftrightarrow$ \\
\hline Şubat & 8.12 & -317 & -1.53 & -9.2 & $\leftrightarrow$ & $\leftrightarrow$ \\
\hline Mart & 26.88 & -59 & -0.28 & 2.4 & $\leftrightarrow$ & $\leftrightarrow$ \\
\hline Nisan & 64.63 & 101 & 0.48 & 14 & $\leftrightarrow$ & $\leftrightarrow$ \\
\hline Mayıs & 66.24 & -153 & -0.74 & 2.3 & $\leftrightarrow$ & $\leftrightarrow$ \\
\hline Haziran & 43.61 & -612 & -2.97 & -36.5 & $\downarrow$ & $\leftrightarrow$ \\
\hline Temmuz & 45.72 & -118 & -0.56 & 1.2 & $\leftrightarrow$ & $\downarrow$ \\
\hline Ağustos & 68.69 & -415 & -2.01 & -24.1 & $\downarrow$ & $\leftrightarrow$ \\
\hline Eylül & 59.48 & 2 & 0.004 & -0.8 & $\leftrightarrow$ & $\leftrightarrow$ \\
\hline Ekim & 24.56 & 186 & 0.89 & 29.4 & $\leftrightarrow$ & $\leftrightarrow$ \\
\hline Kasım & 9.51 & -131 & -0.63 & -0.6 & $\leftrightarrow$ & $\leftrightarrow$ \\
\hline Aralık & 1.93 & -327 & -1.58 & 0.5 & $\leftrightarrow$ & $\leftrightarrow$ \\
\hline Yıllık & 420.74 & -103 & -0.49 & -26.6 & $\leftrightarrow$ & $\leftrightarrow$ \\
\hline
\end{tabular}

Tablo 6. Hergeisa istasyonu istatistiksel test sonuçları ile Şen testinin karşılaştırılması

\begin{tabular}{lccccccc}
\hline Aylar & $\begin{array}{c}\text { Veri } \\
\text { Sayısı }\end{array}$ & $\begin{array}{c}\text { Toplam } \\
\text { Fark }\end{array}$ & $\begin{array}{c}\text { Standart } \\
\text { Hata }\end{array}$ & $\begin{array}{c}\text { Hata } \\
\text { Ortalaması }\end{array}$ & $\begin{array}{c}\text { Test } \\
\text { İstatistiği }\end{array}$ & $\begin{array}{c}\text { \%95 (G.A.) test } \\
\text { (z test 1.96) }\end{array}$ & $\begin{array}{c}\text { Sen Grafik } \\
\text { Testi }\end{array}$ \\
\hline Ocak & 36 & 93.90 & 6.86 & -2.61 & -2.28 & $\downarrow$ & $\downarrow$ \\
\hline Şubat & 36 & 59.70 & 11.34 & 1.66 & 0.88 & $\leftrightarrow$ & $\leftrightarrow$ \\
\hline Mart & 36 & -129.40 & 14.54 & -3.59 & -1.48 & $\leftrightarrow$ & $\leftrightarrow$ \\
\hline Nisan & 36 & 640.00 & 17.01 & 17.78 & 6.27 & $\uparrow$ & $\uparrow$ \\
\hline Mayıs & 36 & 54.80 & 21.49 & 1.52 & 0.42 & $\leftrightarrow$ & $\leftrightarrow$ \\
\hline Haziran & 36 & -731.60 & 7.30 & -20.32 & -16.71 & $\downarrow$ & $\downarrow$ \\
\hline Temmuz & 36 & 42.30 & 10.80 & 1.18 & 0.65 & $\leftrightarrow$ & $\leftrightarrow$ \\
\hline Ağustos & 36 & -633.40 & 10.71 & -17.65 & -9.89 & $\downarrow$ & $\leftrightarrow$ \\
\hline Eylül & 36 & -121.30 & 10.06 & -3.37 & -2.01 & $\downarrow$ & $\uparrow$ \\
\hline Ekim & 36 & 519.90 & 19.47 & 14.44 & 4.45 & $\uparrow$ & $\leftrightarrow$ \\
\hline Kasım & 36 & -13.20 & 5.04 & -0.37 & -0.44 & $\leftrightarrow$ & $\leftrightarrow$ \\
\hline Aralık & 36 & -7.30 & 4.16 & -0.20 & -0.29 & $\leftrightarrow$ & $\leftrightarrow$ \\
\hline Yıllık & 36 & -415.40 & 46.45 & -11.54 & -1.49 & $\leftrightarrow$ & $\leftrightarrow$ \\
\hline
\end{tabular}

Şekil 8 incelendiğinde elde edilen trend değerleri Tablo 6'ya işlendiğinde farkların oluştuğu ayların istatistiksel analize göre düşüş trendi görülen Ağustos ve Eylül ayları olduğu görülmüştür. İstatistiksel olarak incelemede trend oluşup grafiksel olarak gözükmemesindeki sebebin, özellikle Ağustos ayında sadece bir yağış verisinin mevsim normallerinin çok üzerinde olmasıdır. Haziran ayında hem Şen testinde hem test istatistiğinde güçlü azalış trendleri tespit edilmiştir. Ayrıca Mann-Kendall ve 100 yıllık eğilim miktarına bakıldığında da Haziran ayının oldukça güçlü bir azalış eğiliminde olduğu görülmektedir. Yağış ortalaması $43.61 \mathrm{~mm}$ olan Haziran ayında 100 yıllık periyot sonunda 36.5 mm kadar bir azalış öngörülmektedir. Yıllık bazda meydana gelmesi öngörülen $26.6 \mathrm{~mm}$ olan azalıştan daha fazla olan bu değer dikkate alındığında gelecekte Haziran aylarında yağışıı hiç yağmayacağ 1 veya çok az yağacağ 1 gibi bir değerlendirmede bulunulabilir.

\subsection{Burao Bölgesi}

Burao bölgesine ait 58 y1llık veri incelenerek yapılan çalışmada Mann-Kendall trend testine göre Temmuz ve Ağustos aylarında bu trendlerin çok güçlü olduğu görülmüştür (Tablo 7). 100 yıllık eğilimlere bakıldığında ise gelecekte bu aylarda yağış oluşmama ihtimali çok fazladır. Şekil 9'da görüldüğü gibi \%95 güven aralığında sadece 2 aylık bir dönemde azalma trendi görülse de $\% 90$ güven aralığına yakın 2 ay ve yıllık bazda bir azalışın olduğu görülmektedir.

Bölgedeki yağış ölçüm istasyonu incelendiğinde Şen'in grafik testine göre Ocak, Şubat, Temmuz, Ağustos, Kasım ve Aralık aylarında azalan trend mevcut olduğu Ekim ayında ise artış eğilimi olduğu görülmüştür (Tablo 8). Test istatistiğine bakıldığında ise düşük yağış verisine sahip Ocak, Şubat ve Aralık ayındaki azalış trendleri belirlenememiştir (Şekil 10). 

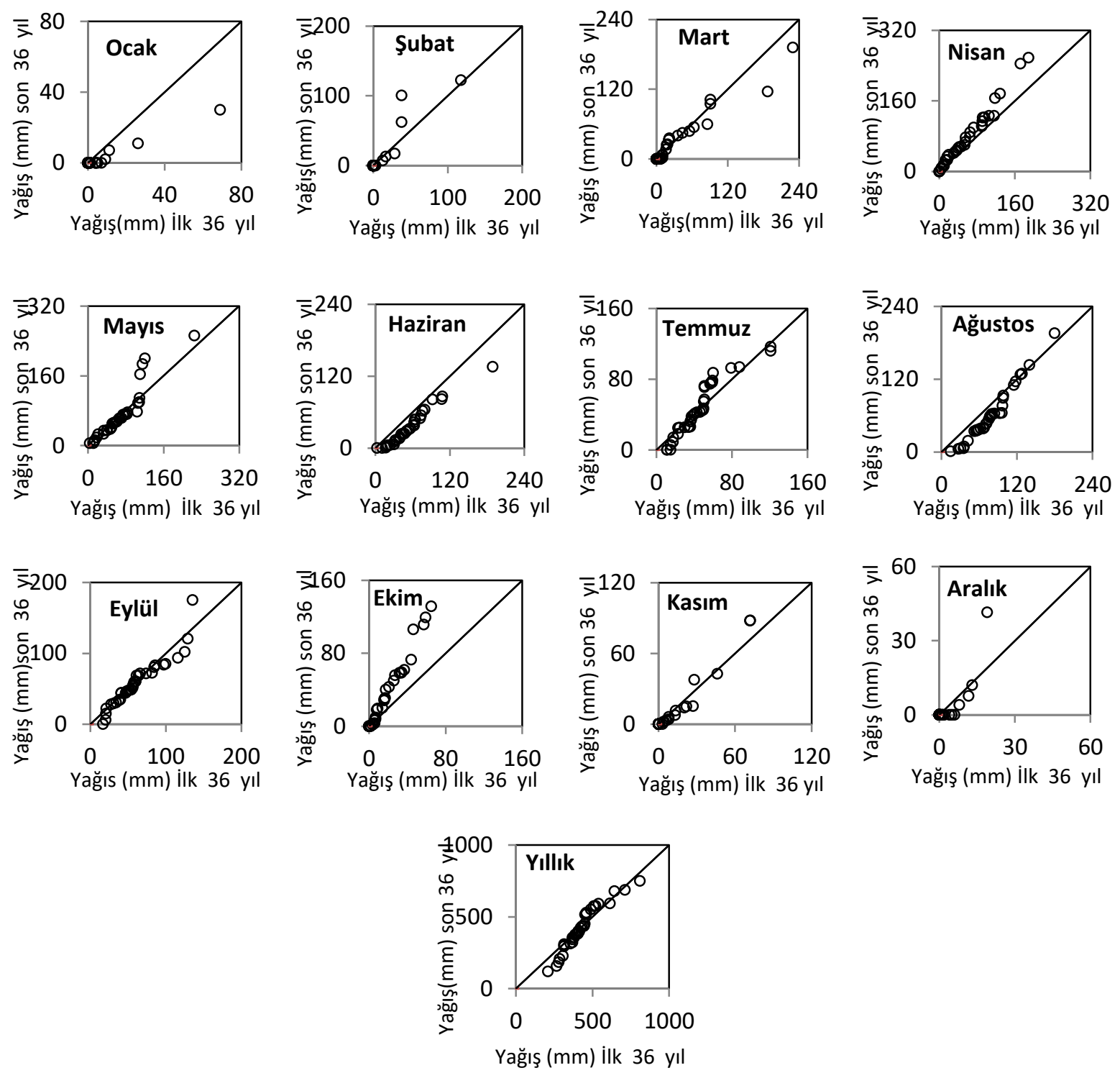

Şekil 1. Hergeisa İstasyonu aylık ve yıllık bazda Şen testi sonuçları

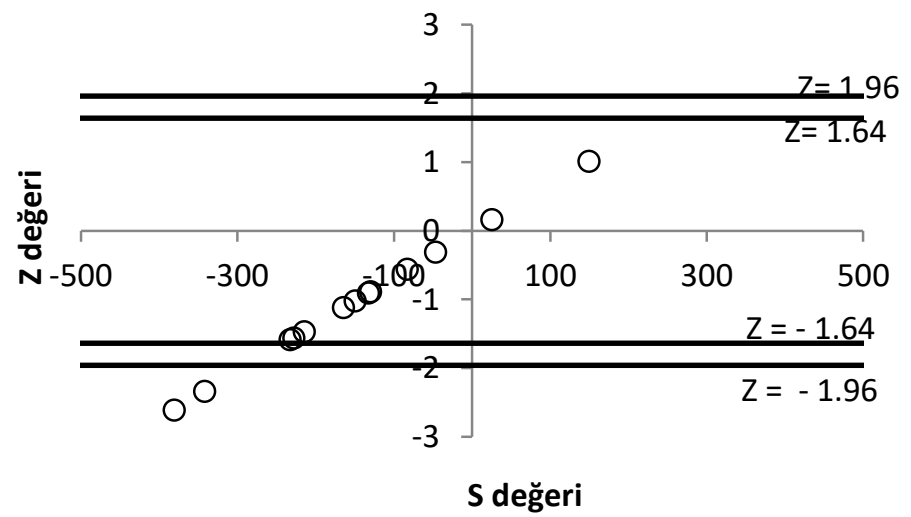

Şekil 9. Burao Bölgesi $\% 90$ ve $\% 95$ güven aralığına göre trendleri 
Tablo 7. Burao Bölgesi Mann-Kendall test istatistiği sonuçları

\begin{tabular}{lcccccc}
\hline Aylar & $\begin{array}{c}\text { Ortalama Yağıș } \\
(\mathbf{m m})\end{array}$ & $\mathbf{S}$ & $\mathbf{Z}$ & $\begin{array}{c}\text { 100Yıllık değ. } \\
(\mathbf{m m})\end{array}$ & $\begin{array}{c}\text { Trend Z } \\
(\mathbf{0 , 9 5})\end{array}$ & $\begin{array}{c}\text { Trend Z } \\
(\mathbf{0 , 9 0})\end{array}$ \\
\hline Ocak & 1.51 & -133 & -0.91 & -3 & $\leftrightarrow$ & $\leftrightarrow$ \\
\hline Şubat & 2.37 & -130 & -0.89 & -0.7 & $\leftrightarrow$ & $\leftrightarrow$ \\
\hline Mart & 7.78 & 25 & 0.16 & 9.9 & $\leftrightarrow$ & $\leftrightarrow$ \\
\hline Nisan & 34.63 & -47 & -0.31 & 2.1 & $\leftrightarrow$ & $\leftrightarrow$ \\
\hline Mayis & 54.35 & -215 & -1.47 & -19 & $\leftrightarrow$ & $\leftrightarrow$ \\
\hline Haziran & 18.78 & -233 & -1.59 & 0.06 & $\leftrightarrow$ & $\leftrightarrow$ \\
\hline Temmuz & 8.96 & -381 & -2.61 & -10.5 & $\downarrow$ & $\downarrow$ \\
\hline Ağustos & 11.73 & -342 & -2.34 & -7.4 & $\downarrow$ & $\downarrow$ \\
\hline Eylül & 24.20 & -165 & -1.12 & -0.6 & $\leftrightarrow$ & $\leftrightarrow$ \\
\hline Ekim & 23.63 & 149 & 1.01 & 12.5 & $\leftrightarrow$ & $\leftrightarrow$ \\
\hline Kasim & 9.71 & -150 & -1.02 & -10.2 & $\leftrightarrow$ & $\leftrightarrow$ \\
\hline Aralık & 1.12 & -83 & -0.56 & -0.6 & $\leftrightarrow$ & $\leftrightarrow$ \\
\hline Y1llk & 198.77 & -228 & -1.56 & -30.2 & $\leftrightarrow$ & $\leftrightarrow$ \\
\hline
\end{tabular}

Tablo 8. Burao istasyonu istatistiksel test sonuçları ile Şen testinin karşılaştırılması

\begin{tabular}{lccccccc}
\hline Yıllar & $\begin{array}{c}\text { Veri } \\
\text { Sayısı }\end{array}$ & $\begin{array}{c}\text { Toplam } \\
\text { Fark }\end{array}$ & $\begin{array}{c}\text { Standart } \\
\text { Hata }\end{array}$ & $\begin{array}{c}\text { Hata } \\
\text { Ortalaması }\end{array}$ & $\begin{array}{c}\text { Test } \\
\text { Istatistiği }\end{array}$ & $\begin{array}{c}\text { \%95 (G.A.) test } \\
\text { (t test 2.04) }\end{array}$ & $\begin{array}{c}\text { Sen Grafik } \\
\text { Testi }\end{array}$ \\
\hline Ocak & 29 & 70.00 & 6.64 & -2.41 & -1.96 & $\leftrightarrow$ & $\downarrow$ \\
\hline Şubat & 29 & 88.00 & 11.06 & -3.03 & -1.48 & $\leftrightarrow$ & $\downarrow$ \\
\hline Mart & 29 & -34.20 & 3.22 & 1.18 & -1.97 & $\leftrightarrow$ & $\leftrightarrow$ \\
\hline Nisan & 29 & 7.00 & 7.83 & 0.24 & 0.17 & $\leftrightarrow$ & $\leftrightarrow$ \\
\hline Mayıs & 29 & 146.80 & 21.22 & 5.06 & 1.28 & $\leftrightarrow$ & $\leftrightarrow$ \\
\hline Haziran & 29 & 160.60 & 32.89 & 5.54 & 0.91 & $\leftrightarrow$ & $\leftrightarrow$ \\
\hline Temmuz & 29 & -135.30 & 6.89 & -4.67 & -3.65 & $\downarrow$ & $\downarrow$ \\
\hline Ağustos & 29 & -226.70 & 8.88 & -7.82 & -4.74 & $\downarrow$ & $\downarrow$ \\
\hline Eylül & 29 & -113.50 & 11.33 & -3.91 & -1.86 & $\leftrightarrow$ & $\leftrightarrow$ \\
\hline Ekim & 29 & 359.30 & 13.60 & 12.39 & 4.90 & $\uparrow$ & $\uparrow$ \\
\hline Kasım & 29 & -220.80 & 12.09 & -7.61 & -3.39 & $\downarrow$ & $\downarrow$ \\
\hline Aralık & 29 & -11.90 & 1.71 & -0.41 & -1.29 & $\leftrightarrow$ & $\downarrow$ \\
\hline Y1llık & 29 & -226.70 & 53.54 & -7.82 & -0.79 & $\leftrightarrow$ & $\leftrightarrow$ \\
\hline
\end{tabular}

\subsection{Erigabo Bölgesi}

Erigabo bölgesinde 34 adet veri üzerinde yapılan çalışmalarda Mann-Kendall trend testine göre Şubat ve Haziran aylarında önemli trendler tespit edilmiştir (Tablo 9). Bu aylarda meydana gelen eğilimlerdeki azalmalarında 100 yıl içerisinde Şubat ayı ve Mayıs ayı yağış ortalamalarının sıfıra yaklaşacağı konusunda önemli deliller sunduğu görülmüştür. Ayrıca eğilim analizleri incelendiğinde Ocak, Ekim, Kasım ve Aralık aylarında ortalama yağış verilerine bakıldığında çok yüksek değişime sahip eğilimler olduğu görülmüsstür. Ancak bu eğilimler Mann-Kendall testinde $\% 90$ ve $\% 95$ güven aralığında bir öneme sahip olmadığından trend oluşmadığ düşünülmüştür. Şekil 11'de görüldügüü gibi 2 adet veri setinde \% 95 güven aralığında azalma eğilimi olduğu gözlemlenmiştir.

Şekil 12 incelendiğinde trendlerin yağışların bol olduğu dönemlerde daha belirgin bir şekilde belirlenebildiği, yağışın çok az yağdığı Aralık ayında belirleyebilmenin çok zor olduğu görülmektedir. Tablo 10 incelendiğinde Şen grafik testine ve bu testin istatistiğine göre bölgede hem aylar bazında hem de yıl genelinde trendlerin mevcut olduğu görülmektedir. $\mathrm{Bu}$ trendlerin 4 tanesi artış yönünde 7 tanesi ise azalış yönündedir. Ancak Temmuz ayındaki artış trendi ile Aralık ayındaki azalış trendi istatistiksel analiz ile desteklenmemektedir. Ayrıca bir önceki bölümde incelenmiş olan Mann-Kendall test istatistiği ile de desteklenmemektedir. 

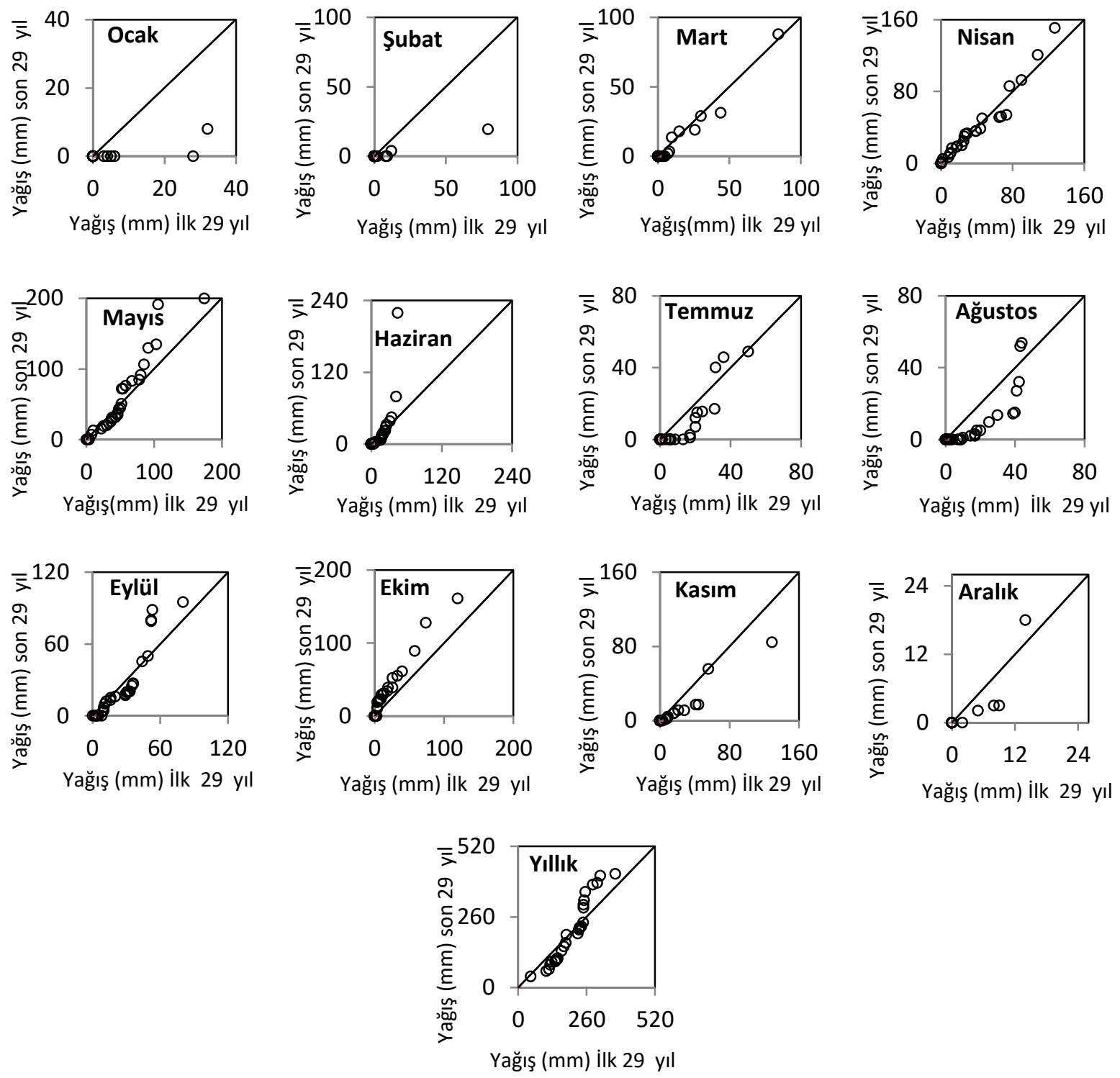

Şekil 10. Burao İstasyonu aylık ve yıllık bazda Şen testi sonuçları

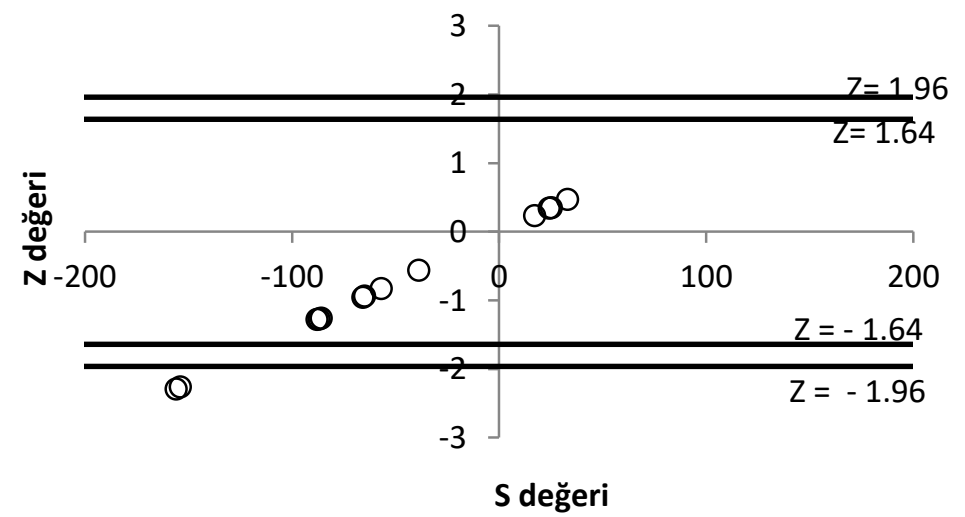

Şekil 11. Erigabo bölgesi $\% 90$ ve $\% 95$ güven aralığına göre trendleri 
Tablo 9. Erigabo Bölgesi Mann-Kendall test istatistiği sonuçları

\begin{tabular}{|c|c|c|c|c|c|c|}
\hline Aylar & $\begin{array}{l}\text { Ortalama } \\
\text { Yağıș (mm) }\end{array}$ & $\mathbf{S}$ & $\mathbf{Z}$ & $\begin{array}{c}100 \text { Yıllık değişim } \\
(\mathrm{mm})\end{array}$ & Trend Z $(0,95)$ & Trend $\mathrm{Z}(\mathbf{0 , 9 0 )}$ \\
\hline Ocak & 7.68 & -66 & -0.96 & -12.8 & $\leftrightarrow$ & $\leftrightarrow$ \\
\hline Şubat & 6.21 & -156 & -2.29 & -13.3 & $\downarrow$ & $\downarrow$ \\
\hline Mart & 20.25 & -57 & -0.83 & -10.9 & $\leftrightarrow$ & $\leftrightarrow$ \\
\hline Nisan & 37.16 & 25 & 0.35 & 15.5 & $\leftrightarrow$ & $\leftrightarrow$ \\
\hline Mayıs & 64.00 & 17 & 0.23 & 15.4 & $\leftrightarrow$ & $\leftrightarrow$ \\
\hline Haziran & 34.43 & -154 & -2.26 & -35.7 & $\downarrow$ & $\downarrow$ \\
\hline Temmuz & 8.99 & -87 & -1.27 & 3.8 & $\leftrightarrow$ & $\leftrightarrow$ \\
\hline Ağustos & 33.58 & 33 & 0.47 & 10.1 & $\leftrightarrow$ & $\leftrightarrow$ \\
\hline Eylül & 74.32 & -65 & -0.94 & -22.6 & $\leftrightarrow$ & $\leftrightarrow$ \\
\hline Ekim & 7.29 & 24 & 0.34 & 11.1 & $\leftrightarrow$ & $\leftrightarrow$ \\
\hline Kasim & 4.34 & -39 & -0.56 & -3.2 & $\leftrightarrow$ & $\leftrightarrow$ \\
\hline Aralik & 0.74 & -88 & -1.28 & -1.9 & $\leftrightarrow$ & $\leftrightarrow$ \\
\hline Y1llik & 298.97 & -86 & -1.26 & -0.04 & $\leftrightarrow$ & $\leftrightarrow$ \\
\hline
\end{tabular}

Tablo 10. Erigabo istasyonu istatistiksel test sonuçları ile Şen testinin karşılaştırılması

\begin{tabular}{lccccccc}
\hline Aylar & $\begin{array}{c}\text { Veri } \\
\text { Sayısı }\end{array}$ & $\begin{array}{c}\text { Toplam } \\
\text { Fark }\end{array}$ & $\begin{array}{c}\text { Standart } \\
\text { Hata }\end{array}$ & $\begin{array}{c}\text { Hata } \\
\text { Ortalaması }\end{array}$ & $\begin{array}{c}\text { Test } \\
\text { Istatistiği }\end{array}$ & $\begin{array}{c}\text { \%95 (G.A.) test } \\
\text { (t test 2.11) }\end{array}$ & $\begin{array}{c}\text { Sen Grafik } \\
\text { Testi }\end{array}$ \\
\hline Ocak & 17 & -9.00 & 6.83 & -0.53 & -0.32 & $\leftrightarrow$ & $\leftrightarrow$ \\
\hline Şubat & 17 & -171.00 & 12.46 & -10.06 & -3.33 & $\downarrow$ & $\downarrow$ \\
\hline Mart & 17 & -239.50 & 11.51 & -14.09 & -5.05 & $\downarrow$ & $\downarrow$ \\
\hline Nisan & 17 & 195.30 & 16.10 & 11.49 & 2.94 & $\uparrow$ & $\leftrightarrow$ \\
\hline May1s & 17 & -82.00 & 17.79 & -4.82 & -1.12 & $\leftrightarrow$ & $\leftrightarrow$ \\
\hline Haziran & 17 & -443.50 & 8.61 & -26.09 & -12.50 & $\downarrow$ & $\uparrow$ \\
\hline Temmuz & 17 & 43.50 & 11.62 & 2.56 & 0.91 & $\leftrightarrow$ & $\uparrow$ \\
\hline Ağustos & 17 & 301.80 & 20.50 & 17.75 & 3.57 & $\uparrow$ & $\uparrow$ \\
\hline Eylül & 17 & -295.20 & 15.65 & -17.36 & -5.58 & $\downarrow$ & $\uparrow$ \\
\hline Ekim & 17 & 72.00 & 7.98 & 4.24 & 2.19 & $\uparrow$ & $\downarrow$ \\
\hline Kasım & 17 & -52.50 & 4.26 & -3.09 & -2.99 & $\downarrow$ & $\downarrow$ \\
\hline Aralık & 17 & -4.00 & 0.73 & -0.24 & -1.33 & $\leftrightarrow$ & $\downarrow$ \\
\hline Y1llık & 17 & -705.10 & 66.27 & -41.48 & -2.58 & $\downarrow$ & $\downarrow$ \\
\hline
\end{tabular}

\section{Tartışma ve Sonuçlar}

Çalışmada Afrika'nın güneydoğusunda bulunan Somali'nin kuzey kısmındaki ortalama olarak oldukça düşük yıllık yağış yüksekliğine sahip olan Somaliland bölgesi çalışılmıştır. Bu bölgeye ait verilerden trend analizi yapilabilecek nitelikte olan 5 adet istasyon seçilerek bunlara ait trendler bulunmaya çalışılmıştır. Bu çalışmalar yapılırken Mann-Kendall trend testi, Şen grafik testi ve bu testin istatistiksel ifadesi olan Saplioğlu istatistiksel analizinden yararlanılmıştır.

Boorama bölgesinde y1llık bazda her üç teste göre de trend oluşumuna rastlanmamışken; Barberea bölgesinde de her üç teste göre de negatif trend elde edilmiştir. Hergesia ve Borao bölgelerinde de trend olmadığı görülmüştür. Ancak Erigabo bölgesinde Mann-Kendall trend analizine göre trend tespit edilmemesine rağmen diğer iki teste göre bir azalma olduğu görülmüştür.

Araştırmada aylık bazda inceleme yapıldığında genelde trendlerin değişmediği; ancak çok sayıda aylık bazda azalma olduğu tespit edilmiştir. Pozitif trendin ise oldukça az olduğu görülmüştür.

Çalışmanın en çok dikkat çekici yanı ise MannKendall testinde görülmeyen trendlerin, Şen testi ve Saplığlu istatistiksel analizlerine göre trendlerinin görülmesidir. Hatta bu analizlerde çok bariz şekilde görülen trendlerin Mann-Kendall testinde gözükmemesidir. Bunun da başlıca sebebi Mann-Kendall testinde farkların büyüklüğünün ağırlık olarak etkisinin olmayışıdır. 

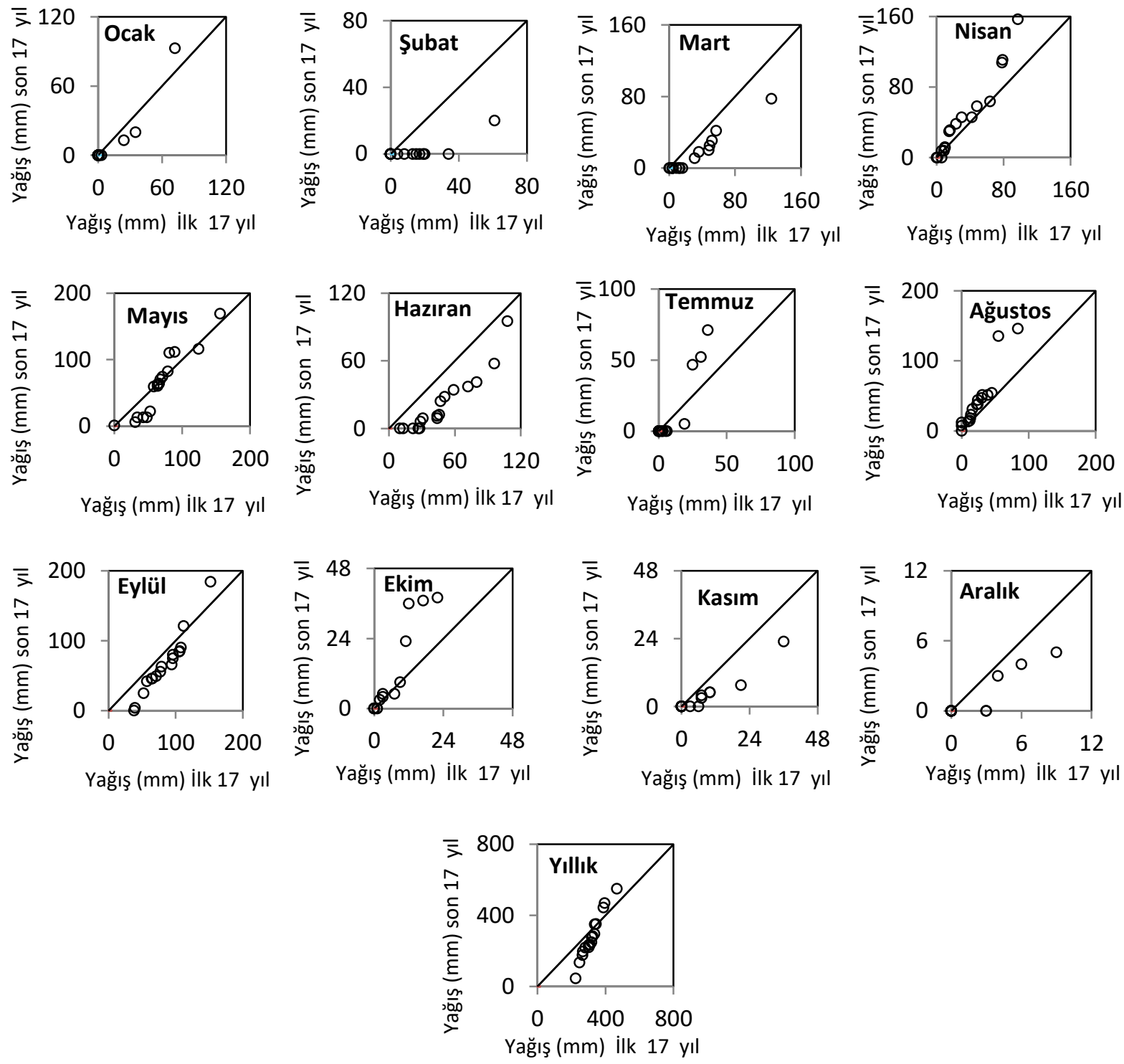

Şekil 12. Erigabo İstasyonu aylık ve yıllık bazda Şen testi sonuçları

\section{Kaynakça}

Ageena, I., Macdonald, N. ve Morse, A., (2014). Variability of maximum and mean average temperature across Libya (1945-2009), Theoretical and Applied Climatology, 117, 549-563.

Baria, S., Rahman, M., Hoqueb, M., \& Hussain, M. (2016). Analysis of seasonal and annual rainfall trends in the northern region of Bangladesh. Atmospheric Research, 176177, 148-158.

Bayazıt, M. ve Önöz, B., (2007). To prewhiten or not to prewhiten in trend analysis?, Hydrological Sciences Journal, 52(4), 611624.
Chen, H., Guo, S., Xu, C. ve Singh, V. P., (2007). Historical temporal trends of hydro-climatic variables and their relevance in water resource management in the Hanjiang basin, Journal of Hydrology, 344, 175-185.

ElNesr, M., Abu-Zreig, M. ve Alazba, A., (2010). Temperature trends and distribution the Arabian Peninsula, American Journal of Environmental Sciences, 6(2), 191-203.

Gocic, M. ve Trajkovic, S., (2013). Analysis of changes in meteorological variables using Mann-Kendall and Sen's slope estimator statistical tests in Serbia, Global and Planetary Change, 100, 172-182.

Gocic, M. ve Trajkovic, S., (2013). Analysis of precipitation and drought data in Serbia 
over the period 1980-2010, Journal of Hydrology, 494, 32-42.

Goswami, B. venugopal, V., Sengupta, D., Madhusoodanan, M. ve Xavier, P., (2006). Increasing trend of extreme rain events over India in a warming environment, $\underline{\text { Science, }}$ $314,1442-1444$.

Gregory, G., (1956). Regional variations in the trends of annual rainfall over the British Isles, The Geographical Journal, 122, 346353.

Jagannathan, R. ve Parthasarathy, B., (1973). Trends and periodick citiles of rainfall over India, Monthly Weather Review, 101, 371375 .

Karmesha, N., (2012). Trend detection in annual temperature ve precipitation using the Mann-Kendall test, Northeastern United States: Master of Environmental Studies Capstone Project.

Kumar, S., Merwade, V., Kam, J., \& Thurner, K. (2009). Streamflow trends in Indiana: Effects of long term persistence, precipitation and subsurface drains. Journal of Hydrology, 374, 171-183.

Mohamed, Y. ve Saavaenije, H. G., (2014). Impact of climate variability on the hydrology of the Sudd wetland: signals derived from long term (1900-2000) water balance computations, Wetlands Ecology and Management, 22, 191-198.

Nasrallah, H. ve Balling, R., (1995). Impact of desertification on temperature trends in the Middle East, Environmental Monitoring and Assessment, 37, 265-271.

Partal, T. ve Kahya, E., (2006). Trend analysis in Turkish precipitation data, Hydrological Proceses, 20, 2011-2026.

Parthasarathy, B. ve Dhar, O., (1974). Secular variations of the rainfallover India, Quarterly Journal of the Royal Meteorological Society, 100, 245-257.

Saplioğlu, K., (2015). A New methodology for trend analysis: A case study in Burdur and Isparta, Turkey, Fresenius environmental Bulletin, 24(10a), 3344-3351.

Satyamurty, P., Anderson de Castro, A., Tota, J., Gularte, L. ve Manzi, A., (2010). Rainfall trends in the Brazilian Amazon Basin in the past eight decades, Theor Appl Climatol (2010) 99:139-148, 99, 139-148.

Singh., P., Kumar, V., Thomas, T. ve Arora, M., (2008). Changes in rainfall and relative humidity in river basins in northwest and central India, Hydrological Processes, 22(16), 2982-2992.

Suzuki, E., (1968). Secular variations of the rainfall in Japan, Papers in Meteorology and Geophysics, 19, 363-399.

Şen, Z., (2012). Innovative trend analysis methodology, Journal of Hydrologic Engineering, 17(9), 1042-1046. .

Şen, Z., (2014). Trend Identification Simulation and Application, Journal of Hydrologic Engineering, 19(3), 635-642.

Tabari, H., Somoe, B. ve Zadeh, M. R., (2011). Testing for long-term trends in climatic variables in Iran, Atmospheric Research, 100, 132-140.

Trajkovic, S. ve Kolakovic, S., (2009). Windadjusted Turc equation for estimating reference, Hydrology Research, 40(1), 4552.

Wang, S., Zhu, J. ve Cai, J., (2004). Interdecadal variability of temperature and precipitation in China since 1880, Advances in Atmospheric Sciences, 21(3), 307-313.

Wikivoyage., (2015). Somaliland. 10 01, 2015 tarihinde

https://en.wikivoyage.org/wiki/Somaliland adresinden alındı

Yue, S. ve Hashino, M., (2003). Long term trends of annual and monthly precipitation in Japan, Journal of the American Water Resources Association, 39, 587-596.

Yue, S., Pilon, P. ve Cavadias, G., (2002). Power of the Mann-Kendall and Spearman's rho tests for detecting monotonic trends in hydrological series, Journal of Hydrology, 259, 254-271.

Yue, S., Pilon, P. ve Cavadias, G., (2002). Power of the Mann-Kendall and Spearman's rho tests for detecting monotonic trends in hydrological series, Journal of Hydrology, 259, 254-271. 